\title{
PENGARUH NILAI BUDAYA SUNDA DALAM UPAYA PENINGKATAN KESEJAHTERAAN PSIKOLOGIS KORBAN BENCANA TANAH LONGSOR
}

\author{
Anissa Lestari Kadiyono \& Diana Harding \\ Fakultas Psikologi, Universitas Padjadjaran \\ anissa.lestari@unpad.ac.id
}

\begin{abstract}
ABSTRAK
Permasalahan psikososial adalah hal yang akan menyertai ketika bencana alam terjadi, termasuk diantaranya adalah bencana tanah longsor yang terjadi di daerah Ciloto Cipanas, Cianjur, Jawa Barat. Daerah ini seringkali mengalami bencana alam, khususnya tanah longsor dikarenakan posisi tanah yang labil dan curah hujan yang tinggi. Pada saat bencana longsor terjadi, maka terdapat korban yang mengakibatkan permasalahan tersendiri bagi pembangunan daerah dan masyarakat dalam melanjutkan hidup mereka. Penelitian ini dilakukan pada korban bencana tanah longsor di Ciloto-Cipanas pada tanggal 21 Januari 2014. Tujuan dari penelitian ini adalah untuk menganalisa nilai apakah dalam diri korban tanah longsor yang dapat meningkatkan kesejahteraan psikologis mereka. Data dikumpulkan melalui interviu mendalam, observasi, diskusi kelompok, dan penyebaran kuesioner. Bagi masyarakat Cianjur, terdapat nilai-nilai dasar yang secara turun-menurun menjadi dasar hidup mereka, yaitu Ngaos, Mamaos, dan Maenpo. Berdasarkan hasil penelitian, nilai Sunda yang penduduk Cianjur anut ini dapat meningkatkan kesejahteraan psikologis, sehingga para korban tanah longsor memiliki semangat untuk melanjutkan hidup dan mewujudkan rencana mereka ke depan. Hal ini dapat dimanfaatkan dalam membuat program intervensi penanganan bencana alam melalui nilai budaya.
\end{abstract}

Kata Kunci : Nilai Religiusitas, Intervensi Psikososial, Kesejahteraan Psikologis, BencanaTanah Longsor

\begin{abstract}
Psychosocial problems had been occured when natural disasters such as landslides in the area Ciloto Cipanas, Cianjur, West Java. These areas often experience natural disasters, especially landslides due to unstable land positions and high rainfall. At the time of landslide disaster, there are victims that cause problems for the economic development and the community in continuing their lives. This research was conducted on the victims of landslide disaster in Ciloto-Cipanas on January 21, 2014. The purpose of this study is to analyzing what values on vulnerable group for lansdslide disasters that can improve their psychological well being using indigenous psychological analysis in Cianjur city. Data collection through in-depth interviews, participatory observation, focus group discussions and questionnaire. For Cianjur people, there are some values that influencing their life: ngaos, mamaos, and maenpo. Based on the research results, the value of Sunda can improve their psychological wellbeing, so they have spirit and courage to move forward and rebuild their future. This finding can be utilized in creating intervention programs for natural disaster management through cultural values.
\end{abstract}

Keywords : Sundanesse Value, Psychosocial Intervention, Psychological Well-Being, Landslide Disasters 


\title{
Journal of Psychological Science and Profesion (JPSP)
}

\author{
Vol.1, No.1, Desember 2017
}

E-mail: jpsp@unpad.ac.id

\section{PENDAHULUAN}

Bencana tanah longsor merupakan bencana yang seringkali terjadi di Indonesia yang merupakan persilangan antara Samudera Indonesia dan Selat Sunda, sehingga hal ini memberikan potensi bencana yang besar dan akan sering terjadi. Salah satu provinsi yang rawan akan bencana adalah Provinsi Jawa Barat. Provinsi Jawa Barat rentan akan terjadinya bencana alam seperti longsor, banjir, gempa, dan angin puting beliung. Menurut data pada Badan Meteorologi Klimatologi dan Geofisika (BMKG) Bandung, Proponsi Jawa Barat, tergolong pada daerah yang masuk klasifikasi rawan longsor dan gerakan tanah. Wilayah-wilayah yang rawan tersebut berada di Kabupaten Bandung, Cianjur, Sukabumi, Garut, Sumedang, Majalengka, Ciamis dan Kuningan. Diantara propinsi lain di Indonesia, Propinsi Jawa Barat tergolong zona merah dan menduduki ranking pertama terhadap ancaman longsor.

Bencana alam dapat menimbulkan kerugian dan penderitaan yang cukup berat sebagai akibat dari perpaduan bahaya alam dan kompleksitas permasalahan lainnya. Korban jiwa manusia yang meninggal maupun cedera, runtuhnya bangunan-bangunan pemerintah dan swasta, rusaknya sarana prasarana, jaringan utilitas, dan infrastruktur serta kerugian moril yang tidak terhitung jumlahnya merupakan akibat yang timbul dari berbagai kejadian bencana tersebut.

Salah satu bencana alam yang terjadi di Jawa Barat pada awal tahun 2014 adalah bencana tanah longsor dan pergerakan tanah yang terjadi pada tanggal 21 Januari 2014 di daerah CilotoCipanas Kabupaten Cianjur, meskipun tidak sampai menimbulkan korban jiwa, namun telah banyak menimbulkan kerusakan dan kerugian harta benda. Daerah Ciloto Cipanas merupakan permukiman padat penduduk, berkontur miring, curah hujan tinggi, suhunya dingin dan berkabut tebal. Rumahrumah penduduk yang rusak total akibat terjadinya bencana longsor, tidak bisa ditempati lagi, sehingga para korban bencana terpaksa mengungsi ke tempat yang aman. Data dari hasil pemetaan yang dilakukan tim dari Lembaga Kesejahteraan Sosial (LKS) Socindo Cianjur, tercatat sebanyak 46 KK atau 213 orang sebagai korban tanah longsor dan pergerakan tanah. Saat terjadi bencana para warga yang terpapar bencana ditampung atau diungsikan di beberapa tempat, dan diantara lokasi yang paling banyak menampung adalah gedung Sekolah Dasar (SD) Ciloto. Di SD Ciloto, yang terdiri dari tiga ruangan kelas, menampung sebanyak 150 orang. Sisanya ada yang menumpang di sanakkeluarga atau tetangga (LKS SOCINDO, 6 Pebruari 2014).

Para korban bencana longsor, hidup di lokasi pengungsian dalam kondisi serba kekurangan. Mereka menempati gedung Sekolah Dasar dengan pakaian, harta, dan makanan seadanya, kehidupan mata pencaharian menjadi terganggu, sehingga kesempatan untuk memenuhi kebutuhan dasarnya pun menjadi sangat terbatas. Dengan keterbatasan pemenuhan kebutuhan pokok ini tentu saja juga diikuti dengan keterbatasan pemenuhan kebutuhan lainnya. Selain itu, sebagian korban bencana juga mengalami masalah psikososial sebagai dampak dari peristiwa bencana yang terjadi, antara lain; sulit tidur, gangguan selera makan, gangguan konsentrasi dalam belajar, mudah tersinggung, sedih, duka yang mendalam, dan merasa tidak berdaya. Kondisi yang demikian dapat menyebabkan terganggunya atau menurunnya well-being pada diri korban. Badan Nasional Penanggulangan Bencana (BNPB) menyatakan bahwa upaya dalam melakukan mitigasi bencana adalah dengan menghindari daerah rawan bencana untuk pembangunan permukiman dan fasilitas utama lainnya. Namun, tentu saja hal ini sulit untuk dijalani. Kesedihan, kehilangan, kekecewaan, dan trauma dapat dialami oleh para korban bencana alam. Diperlukan upaya bagi para korban agar dapat bangkit kembali dan menata hidup kembali menjadi produktif. Bencana alam yang tidak dapat dipastikan kapan datang dan perginya membuat masyarakat harus memiliki kewaspadaan dan ilmu mengenai bencana alam. Selain persiapan material, juga diperlukan persiapan mental dan strategis yang harus dilakukan ketika musibah terjadi.

Dalam menghadapi bencana tersebut, masyarakat Cianjur memiliki nilai dasar yaitu Ngaos, Mamaos, dan Maenpo (cianjurkab.go.id). Hal ini menunjukkan bahwa masyarakat Cianjur menjunjung tinggi nilai keagamaan Islam, Kesenian, dan Olahraga khususnya Beladiri. Ngaos adalah tradisi mengaji yang mewarnai suasana dan nuansa Cianjur dengan masyarakat yang dilekati dengan ke beragamaan. Citra sebagai daerah agamis ini bahkan menjadi visi Kota Cianjur. Sedangkan Mamaos adalah seni budaya yang menggambarkan kehalusan budi dan rasa menjadi perekat persaudaraan dan kekeluargaan dalam tata pergaulan hidup. Pada umumnya syair mamaos ini lebih banyak mengungkapkan puji-pujian akan kebesaran Tuhan dengan segala hasil ciptaan-Nya. Sedangkan Maenpo adalah seni diri pencak silat yang menggambarkan keterampilan dan ketangguhan. Apabila 


\title{
Journal of Psychological Science and Profesion (JPSP)
}

\author{
Vol.1, No.1, Desember 2017
}

E-mail: jpsp@unpad.ac.id

filosofi tersebut diresapi, pada hakekatnya merupakan symbol rasa keber-agama-an, kebudayaan dan kerja keras. Dengan keber-agama-an sasaran yang ingin dicapai adalah terciptanya keimanan dan ketaqwaan masyarakat melalui pembangunan akhlak yang mulia. Dengan kebudayaan, masyarakat cianjur ingin mempertahankan keberadaannya sebagai masyarakat yang berbudaya, memiliki adab, tatakrama dan sopan santun dalam tata pergaulan hidup. Oleh karenanya, nilai religiusitas ini diangkat menjadi salah satu intervensi psikososial dalam upaya meningkatkan kesejahteraan psikologis korban bencana longsor.

Menurut Schwartz (1994), nilai merupakan sesuatu yang digunakan individu dalam memilih dan membenarkan perilaku serta mengevaluasi tindakan orang lain (termasuk diri sendiri) dan peristiwa. Nilai-nilai yang dipegang oleh individu menjadi dasar bagi mereka dalam mengevaluasi sebuah kejadian sehingga memberikan pemaknaan terhadap kejadian tersebut, termasuk kejadian bencana alam.Nilai budaya yang diadaptasi dari Schwartz (2007)melihat inti dari kebudayaan sebagai nilai-nilai yang diyakini baik atau buruk, apa yang mereka pikir harus dan tidak harus dikerjakan, apa yang mereka dambakan atau tidak mereka dambakan. Nilai-nilai kebudayaan ini merupakan dasar yang spesifik untuk mengharapkan orang-orang bertingkah laku secara benar pada waktu yang tepat.Nilaibudayainimeliputi Intellectual Autonomy, Affective Autonomy, Embeddedness, Hierarchy, Harmony, dan Mastery.

Pada korban bencan alam, maka kesejahteraan selaku manusia lah yang paling terusik dengan adanya bencana alam tersebut. Kesejahteraan Psikologis atau Psychological Well-being merupakan kondisi tentang perasaan sejahtera atau perasaan keadaan baik yang dialami seseorang. Kondisi psikologis masyarakat yang sehat adalah individu yang mempunyai sikap positif, mempunyai pandangan yang baik terhadap diri sendiri maupun segala sesuatunya dan mampu mengatasi suatu masalah. Hal ini berarti memiliki psychological well-being. Lebih jelasnya, segala aktivitas yang dilakukan oleh individu yang berlangsung setiap hari dimana dalam proses tersebut kemungkinan mengalami fluktuasi pikiran dan perasaan yang dimulai dari kondisi mental negatif sampai pada kondisi mental positif, misalnya dari trauma sampai penerimaan hidup dinamakan psychological wellbeing (Bradburn dalam Ryff \& Keyes,1995).

Psychological Well Being dapat dilihat dari persepsi individu terhadap pengalamanpengalaman hidupnya bahwa ia mampu melakukan penerimaan diri (Self-Acceptance), mampu menjalin relasi positif dengan orang lain (Positive Relation with Others), mampu bersikap mandiri (Autonomy), mampu menguasai lingkungannya (Environmental Mastery), memiliki tujuan hidup (Purpose in Life) dan juga mampu melakukan pengembangan diri (Personal Growth) serta secara sukses mengatasi segala tantangan dan kesulitan yang ada dalam hidup mereka (Ryff and Singer, 2002).Secara umum, tujuan dari penelitian ini adalah meneliti hubungan Nilai Budaya Sunda dan Psychological Well-being pada masyarakat yang terkena bencana tanah longsor di Ciloto-Cianjur, Jawa Barat.

\section{METODE}

Subjek penelitian adalah korban bencana tanah longsor di Ciloto Cianjur, Jawa Barat yang berada pada usia produktif, yaitu berusia antara 18-60 tahun. Sampel penelitian sejumlah 81 orang yang terdiri atas responden wanita sebanyak 58 orang $(72 \%)$ dan responden pria sebanyak 23 orang (28\%).Berikutadalah data umumrespondenpenelitian :

Tabel 1. Data Demografi Responden Penelitian

\begin{tabular}{clcc}
\cline { 2 - 4 } & \multicolumn{1}{c}{ Kategorisasi } & Persentase & Jumlah \\
\hline \multirow{3}{*}{ Jenis Kelamin } & Perempuan & $72 \%$ & 58 \\
\cline { 2 - 4 } & Laki-Laki & $28 \%$ & 23 \\
\hline \multirow{2}{*}{ Usia } & Young Adulthood & $22 \%$ & 18 \\
\cline { 2 - 4 } & Middle Aged Adulthood & $57 \%$ & 46 \\
\cline { 2 - 4 } & Older Adulthood & $21 \%$ & 17 \\
\hline
\end{tabular}




\section{Journal of Psychological Science and Profesion (JPSP)}

Vol.1, No.1, Desember 2017

E-mail: jpsp@unpad.ac.id

\begin{tabular}{llcc}
\cline { 2 - 4 } & SD/Sederajat & $33 \%$ & 27 \\
\cline { 2 - 4 } & SMP/Sederajat & $25 \%$ & 20 \\
\cline { 2 - 4 } Pendidikan Terakhir & SMA/Sederajat & $41 \%$ & 33 \\
\cline { 2 - 4 } & S1 & $1 \%$ & 1 \\
\hline & Kawin & $68 \%$ & 55 \\
\cline { 2 - 4 } Status Perkawinan & Belum Kawin & $6 \%$ & 5 \\
\cline { 2 - 4 } & Janda & $26 \%$ & 21 \\
\hline
\end{tabular}

Penelitian ini menggunakan metode kuantitatif dengan menggunakan pendekatan deskriptif kuantitatif. Karena hanya menggambarkan suatu keadaan, gambaran umum, fakta dan fenomena yang ada. Data yang terkumpul diwujudkan dalam bentuk angka-angka kemudian diolah dengan menggunakan analisis stastistik. Angka korelasi akan menunjukkan sejauh mana dua hal saling berhubungan. Teknik analisis yang digunakan adalah korelasi Pearson menggunakan software Statistical Package for Social Science (SPSS) 22.0 for Windows.

Nilai Budaya Sunda diukur melalui adaptasi teori nilai dari Schwartz (2004)yang mengeluarkan Cultural Values Orientation (CVO) yang diadaptasipadanilaiBudayaSunda yang dianutpadamasyarakatCianjur, yaituNgaos, Mamaos, danMaenpo. NilaiBudayainimeliputi Intellectual Autonomy, Affective Autonomy, Embeddedness, Hierarchy, Harmony, dan Mastery.

Psychological Well-Being diukurmenggunakanteoripsychological well-beingyang dijelaskan melalui 6 dimensi menurut Carol D. Ryff (1989)dalam Springer \& Hauser (2006), yaitu penerimaan diri, hubungan positif dengan orang lain, otonomi, penguasaan lingkungan, tujuan hidup, dan perkembangan pribadi.

Skor total yang diisi oleh individu akan menggambarkan kondisi psychological well-being individu apakah berada pada tingkat psychological well-being tinggi, cenderung tinggi, cenderung rendah, atau rendah. Selain itu juga hasil kuesioner ini dapat menggambarkan tinggi rendahnya setiap dimensi dari psychological well-being itu sendiri dari setiap individu. Namun dalam pembahasannya, tidak dibahas setiap individu melainkan dibahas secara komunitas sehingga dapat merepresentasikan gambaran psychological well-being korban longsor di Ciloto, Cianjur- Jawa Barat.

\section{HASIL PENELITIAN}

Kebahagiaan secara Psikologis sejatinya belum tercapai sepenuhnya oleh masyarakat Ciloto yang pernah mengalami bencana tanah longsor, mereka masih merasakan trauma yang berkepanjangan, merasakan masa lalu bukan hal yang menyenangkan bagi dirinya. Mereka sering merasa kesepian dan kegiatan sehari-hari bukan sesuatu yang penting bagi mereka, bahkan mereka tidak tahu lagi apa yang sebenarnya ingin mereka capai dalam hidupnya, kadangkala mereka merasa tidak ada orang lain yang mau mendengarkan saat mereka berbicara atau mengungkapkan perasaannya kepada orang lain.

Psychological Well-Being merupakan penilaian individu berdasarkan persepsinya terhadap pengalaman-pengalaman hidupnya bahwa ia mampu melakukan penerimaan diri (Self-Acceptance), mampu menjalin relasi positif dengan orang lain (Positive Relation with Others), mampu bersikap mandiri (Autonomy), mampu menguasai lingkungannya (Environmental Mastery), memiliki tujuan hidup (Purpose in Life) dan juga mampu melakukan pengembangan diri (Personal Growth) serta secara sukses mengatasi segala tantangan dan kesulitan yang ada dalam hidup mereka (Ryff and Singer, 2002). Kondisi bahagia seperti yang diungkapkan Ryff and Singer tahun 2002 ini tampaknya belum sepenuhnya tercapai oleh Masyarakat Ciloto yang pernah mengalami bencana tanah longsor, karena pengalaman-pengalaman hidupnya yang memporak porandakan dan menakutkan. Psychological Well-Being yang dimiliki masyarakat korban bencana tanah longsor berada dalam kategori cenderung rendah (94.64\%).

Psychological Well-being adalah dorongan untuk menggali potensi diri individu secara keseluruhan. Ryff (dalam Allan Car, 2008). Dorongan tersebut dapat menyebabkan seseorang 


\section{Journal of Psychological Science and Profesion (JPSP)}

Vol.1, No.1, Desember 2017

E-mail: jpsp@unpad.ac.id

menjadi pasrah terhadap keadaan yang membuat psychological well-being individu menjadi rendah sebaliknya individu dapat pula berusaha untuk memperbaiki keadaan hidup yang akan membuat psychological well-being individu tersebut menjadi tinggi (Ryff \& Keyes, 1995). Berdasarkan hasil pengukuran didapatkan hasil sebagai berikut :

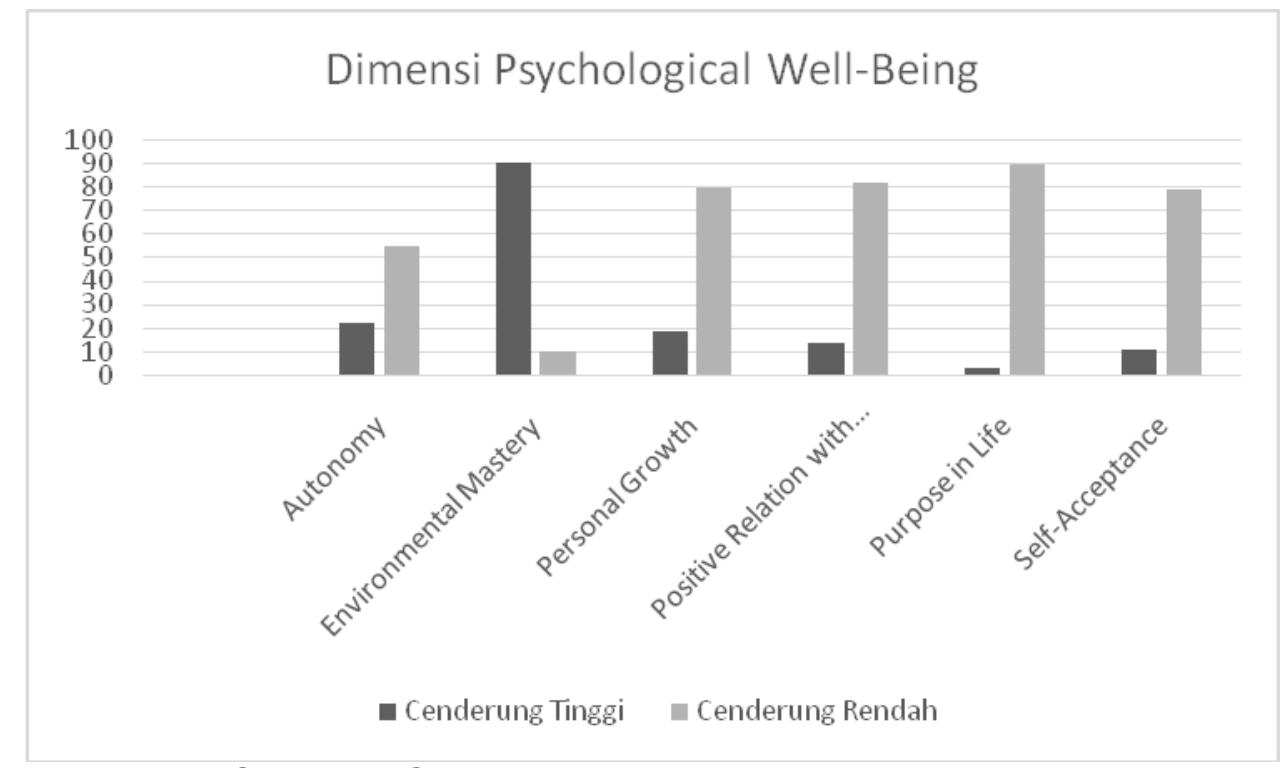

Gambar 1. Gambaran Dimensi Psychological Well-Being

Dimensi Purpose in Life merupakan dimensi yang paling rendah pada masyarakat korban longsor. Masyarakat memiliki perasaan bahwa tidak ada tujuan yang ingin dicapai dalam hidup, tidak melihat adanya manfaat dalam masa lalu kehidupannya, dan tidak mempunyai kepercayaan yang dapat membuat hidup lebih berarti.Dimensi ini menjelaskan kemampuan individu untuk menemukan makna dan arah kehidupan berdasarkan perngalaman pribadi, dan untuk menyusun tujuan hidupnya (Ryff \& Singer, 2002). Individu yang memiliki nilai yang baik dalam dimensi ini adalah inividu yang memiliki target dan cita-cita dalam hidupnya serta merasa bahwa kehidupan di saat ini dan masa lalunya bermakna. Individu tersebut juga memegang teguh pada suatu kepercayaan tertentu yang dapat membuat hidupnya lebih berarti.Namun hal ini tidak dimiliki oleh masyarakat korban bencana tanah longsor Ciloto-Cianjur.

Selain purpose in life, Dimensi Positive Relationship with Other, Personal Growth danSelf Acceptance juga memiliki skor yang rendah. Dimensi Self Acceptance merupakan ciri utama kesehatan mental dan juga sebagai karakterisitik utama dalam aktualisasi diri, kematangan dari individu yang berfungsi optimal. Penerimaan diri yang baik ditandai dengan kemampuan menerima diri apa adanya. Kemampuan tersebut memungkinkan seseorang untuk bersikap positif terhadap diri sendiri dan kehidupan yang dijalani. Namun masyarakatkorbanbencanalongsorsetelah mengalami bencana tidak lagi menghayati dirinya mampu melakukan penerimaan diri, mereka tidak lagi memiliki sikap yang positif pada diri sendiri, tidak menerima diri secara positif dan memandang masa lalunya sebagai penderitaan. Individu yang menghayati dirinya tidak mampu melakukan penerimaan diri akan merasa tidak puas terhadap diri sendiri, kecewa dengan masa lalu dan ingin menjadi orang yang berbeda dari dirinya saat ini. Merasa tidak memiliki kesempatan untuk berkembang dan tidak memiliki lingkungan sosial yang dapat menjalani relasi secara hangat dan terpercaya untuk dapat membantunya melewati masa-masa sulit ini.

Satu-satunya dimensi yang memiliki skor berada dalam kategori cenderung tinggi adalah Environmental Mastery. Kemampuan pada aspek ini menunjukkan bahwa masyarakat korban longsor Ciloto-Cianjur mampu menciptakan dan mempertahankan lingkungan yang memberikan manfaat positif bagi dirinya. Mereka menguasai lingkungannya, terlebih bencana longsor telah menjadi kondisi yang terjadi secara berulang dari tahun ke tahun. Mereka mampu mengatur lingkungannya serta melakukan perbaikan pada lingkungan agar situasi longsor dapat dikondisikan dan tidak mengganggu kehidupan masyarakat desa secara umum. Hal ini pula yang membuat mereka tidak mau pindah dari 


\title{
Journal of Psychological Science and Profesion (JPSP)
}

\author{
Vol.1, No.1, Desember 2017
}

E-mail: jpsp@unpad.ac.id

lingkungannya saat ini. Meski pemerintah telah memberikan jalan dengan rencana relokasi desa ke wilayah yang lebih aman, namun masyarakat menganggap bahwa lingkungan yang di tempati saat ini adalah lingkungan yang terbaik karena dekat dengan tempat kerja, tempat berusaha, dan tempat berkumpul antar sesame saudara.

Di Ciloto-Cianjur, masyarakatnya hidup dalam budaya Sunda. Pada daerah Cianjur, terdapat 3 pilar budaya Cianjur, yaitu Ngaos, Mamaos, dan Maenpo. Ngaos adalah tradisi mengaji yang mewarnai suasana dan nuansa cianjur dengan masyarakat yang dilekati dengan keberagamaan. Mamaos adalah seni budaya yang menggambarkan kehalusan budi dan rasa menjadi perekat persaudaraan dan kekeluargaan dalam tata pergaulan hidup. Sedangkan Maenpo adalah seni bela diri pencak silat yang menggambarkan keterampilan dan ketangguhan. Apabila filosofi tersebut diresapi, pada hakekatnya merupakan symbol rasa keberagamaan, kebudayaan dan kerja keras.

Nilai-nilai budaya Sunda ini diadaptasi pada nilai budaya yang dikemukakan oleh Schwartz (1999). Nilai budaya adalah keyakinan dasar yang orang berpendapat apa yang benar dan salah, baik dan buruk, yang penting dan tidak penting dan nilai-nilai ini diadaptasi dari budaya di mana individu dipelihara, dan budaya membantu untuk mengarahkan perilaku seseorang. Intellectual Autonomy adalah dorongan setiap individu untuk membuat suatu gagasan ide dari setiap individu guna untuk membuat rancangan kegiatan kehidupan secara intelektual dan mandiri dalam suatu kelompok. Sedangkan Affective Autonomy adalah suatu dorongan setiap individu untuk membuat suatu kegiatan sehari-hari berdasarkan pengalaman yang sudah didapat oleh setiap individu untuk membuat ketertarikan pada indiviu lain. Embeddedness memberikan penekanan pada penanaman kehidupan sosial dalam masyarakat tertanam secara kolektivitas sehingga menciptakakan kehidupan sosial secara berkelompok untuk mencapai tujuan hidup dimana disebut dengan tradisi. Hierarchy memberikan dorongan individu untuk bergantung pada peran-peran yang bertanggung jawab dan berperilaku secara produktif. Dalam hal ini hirarki didefinisikan sebagai distribusi kekuasaan, peran penting, dan sumber daya. Harmony memberikan suatu dorongan dari individu kepada khalayak luas untuk memahami tradisi budaya mereka, menghargai setiap tradisi budaya yang dijalankan dan untuk mengekploitasi peran penting tradisi budaya yang mereka percayai dimana tradisi budaya meliputi perdamaian, kesatuan, dan melindungi alam. Sedangkan mastery merupakan sebuah respon dari setiap individu kepada khayalak luas dalam penguasaan secara hakiki mengenai perubahan lingkungan alam maupun sosial untuk tujuan individu atau kelompok masyarakat dalam menjalankan tradisi budaya.

Berdasarkan hasil penelitian maka didapatkan hasil sebagai berikut : 


\section{Journal of Psychological Science and Profesion (JPSP)}

Vol.1, No.1, Desember 2017

E-mail: jpsp@unpad.ac.id

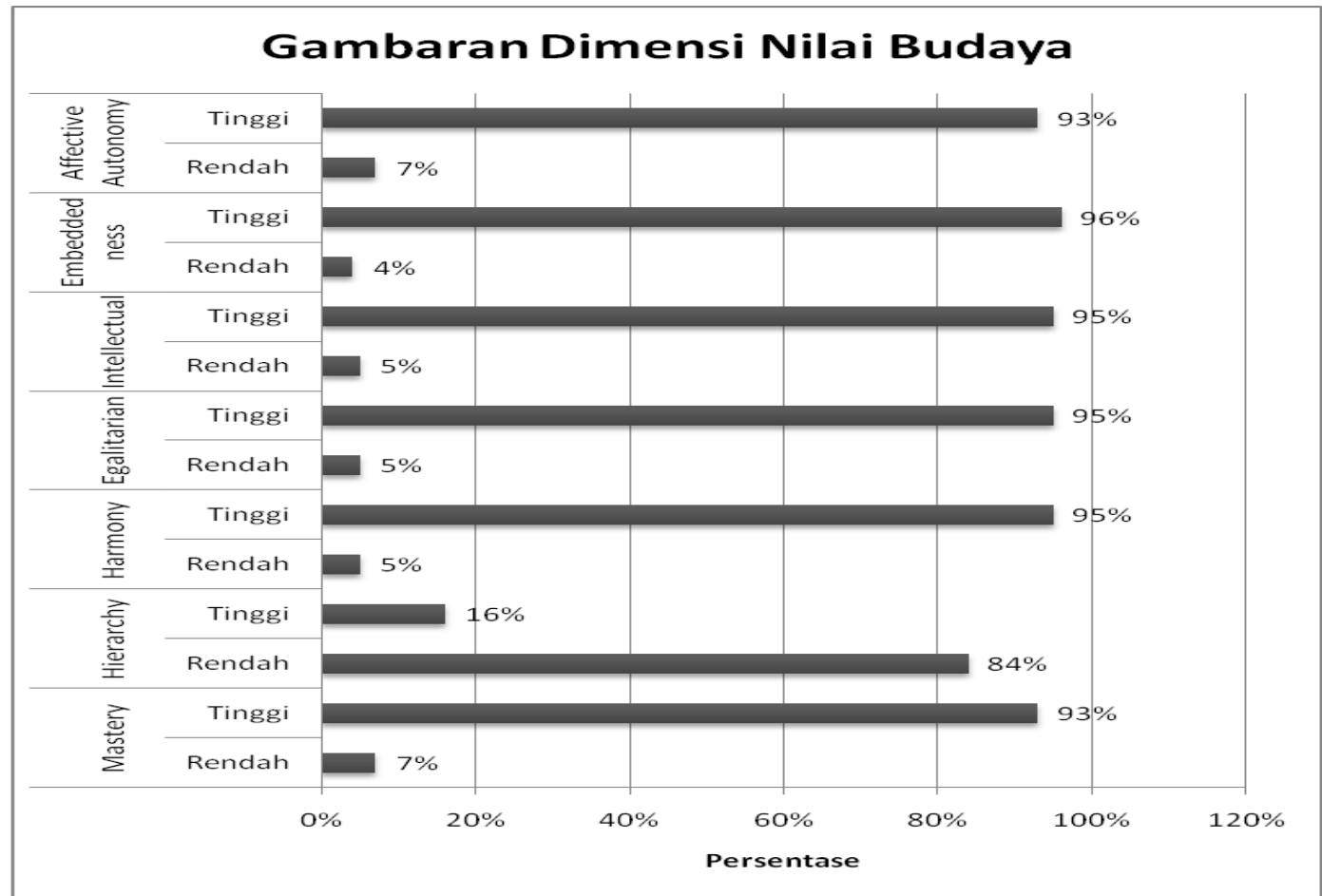

Gambar 2. GambaranDimensiNilaiBudaya

Nilai budaya Sunda yang dianut oleh masyarakat Ciloto-Cianjur memiliki makna bahwa mereka memiliki keikatan yang kuat sebagai orang Sunda yang memiliki nilai Ngaos, Mamaos, dan Maenpo baik secara individual maupun hidup bermasyarakat untuk hidup secara berdampingan (harmony), dan juga dapat mencapai tujuannya sendiri dengan melakukan keterampilan yang dimilikinya (mastery), juga dalam memenuhi kebutuhannya mencapai ide-idenya sendiri (Intellectual autonomy), maupun mewujudkan pengalaman positif dalam hidupnya (Affective autonomy), maupun merasa bagian dari orang Sunda yang memiliki tradisi, adat, dan kebiasaan tersendiri (embeddedness). Nilai egaliter dalam budaya Sunda yang mereka anut juga mendorong setiap orang untuk saling mengenali satu sama lain dikarenakan nasib yang sama dan memiliki kepentingan dasar sebagai manusia. Namun hal ini tidak dibarengi dengan adanya distribusi peran untuk mematuhi kewajiban dan peraturan yang melekat padanya sebagai orang Sunda. Nilai Hierarchy yang rendah menunjukkan kurangnya rasa hormat pada atasan/ tetua dan kepercayaan pada pimpinan untuk membagi tugas agar mereka dapat berperilaku produktif. Unsur-unsur kepemimpinan lemah di bagian ini dan membutuhkan intervensi psikososial dalam penanganannya.

Berdasarkan analisis statistik maka dapat diketahui bahwa Nilai Budaya Sunda memiliki hubungan yang signifikan dengan Psychological Well-being, dengan korelasi sebesar 0.594 atau berada dalam kategori kuat. Uji regresi yang dilakukan juga menunjukkan adanya pengaruh Nilai Budaya terhadap pembentukan Psychological Well-being. Nilai Budaya dapat memberikan 35.3\% pengaruh terhadap pembentukan Psychological Well-Being. Hal ini menunjukkan bahwa Nilai Budaya Sunda dapat digunakan sebagai bahan intervensi psikososial untuk meningkatkan Psychological Well-being para korban bencana longsor di Ciloto-Cianjur, Jawa Barat.

Secara deskriptif, nilai budaya para korban bencana longsor Cianjur berada dalam kategori tinggi, sedangkan Psychological well-being mereka berada dalam kategori cenderung rendah. Hal ini menunjukkan bahwa para korban bencana longsor memiliki nilai budaya yang mempengaruhi perilakunya secara individual maupun secara berkelompok yang mewarnai ciri khasnya dalam mengambil keputusandanbersikap. Namun dilihat dari Psychological well-being yang mereka miliki, para korban longsor Ciloto belum memiliki sikap positif terhadap diri dan orang lain. Mereka belum mampu membuat keputusan sendiri, dan mengatur tingkah laku mereka, serta mereka belum mampu memilih dan membentuk lingkungan yang sesuai dengan kebutuhan mereka. Setiap responden 


\title{
Journal of Psychological Science and Profesion (JPSP)
}

\author{
Vol.1, No.1, Desember 2017
}

E-mail: jpsp@unpad.ac.id

tampaknya belum memiliki tujuan yang berarti dalam hidupnya, dan mereka juga tidak berusaha untuk menggali dan mengembangkan diri mereka semaksimal mungkin.

Psychological Well Being secara umum dapat diartikan sebagai suatu bentuk kepuasan terhadap aspek-aspek hidup sehingga mendatangkan atau menimbulkan perasaan bahagia dan perasaan damai pada hidup seseorang, namun standar kepuasan pada setiap orang berbeda sehingga hal ini bersifat subjektif. MasyarakatCiloto-Cianjurbelum mampu menghayati dirinya untuk bersikap mandiri termasuk dalam hal pengambilan keputusan akan bersikap mandiri, kurang mampu mempertahankan diri dari tekanan pengaruh luar (tidak konformis) dan untuk berpikir dalam cara-cara tertentu, mereka pun belum mampu mengatur diri dan mampu mengevaluasi diri sesuai dengan standar pribadi (Ryff dan Keyes, 1995).Individuyang menghayati dirinya tidak mampu bersikap mandiri termasuk dalam hal pengambilan keputusan akan terlalu memperhatikan harapan dan evaluasi dari luar, bersandar pada penilaian orang lain untuk membuat keputusan penting, berperilaku konform terhadap tekanan sosial untuk berpikir dan bertindak dalam cara tertentu (Ryff dan Keyes, 1995).

Hal ini diperkuat dengan lemahnya nilai hierarchy pada Nilai budaya mereka, dimana kurang adanya kepercayaan pada pimpinan atau pemerintah dalam menangani permasalahan mereka yang membuat mereka cenderung bertindak sendiri sesuai dengan penilaian kebutuhan mereka. Kondisi ini juga yang membuat rencana pemerintah memindahkan penduduk ke daerah Cikalong tidak berhasil. Masyarakat menilai bahwa meski pemerintah telah memberikan lahan pengganti di Cikalong, tetapi pemberian lahan itu sangat tidak sesuai karena berada ditengah hutan yang sepi, dimana mereka tidak bisa bekerja lagi. Sementara di daerah Ciloto tempat tinggal mereka sebelum terkena bencana, tersedia banyak sekali lahan untuk mencari pekerjaan, apakah menjadi penjaga Vila, pelayan di Hotel atau restauran, atau bekerja di pabrik susu, atau bahkan menggarap lahan untuk ditanami sayuran yang hasilnya dibagi dua dengan pemilik lahan. Atas dasar itulah, penduduk meninggalkan tempat pemukiman baru yang diberikan oleh Pemerintah setempat, dan kembali menempati rumah rumah yang sudah hancur akibat longsor.

Menurut Schwartz (2012), nilai yang dimiliki oleh seseorang mempunyai derajat kepentingan dan memberikan panduan dalam hidup seseorang. Nilai yang dianut oleh seseorang bisa saja sama dengan orang lain, tetapi derajat kepentingan dari nilai yang membedakannya dengan orang lain memungkinkan setiap orang memiliki pandangan yang berbeda terhadap sebuah peristiwa. Schwartz (1992) menjelaskan bahwa yang membedakan antara satu nilai dengan nilai yang lain terletak pada tujuan motivasional yang diekspresikan oleh nilai tersebut. Tujuan motivasional setiap nilai berasal dari kebutuhan universal manusia, yaitu kebutuhan individu sebagai organisme biologis kebutuhan untuk menjalin interaksi sosial, dan kebutuhan untuk mempertahankan kelangsungan hidup dari kelompok (Schwartz, 1994).

Schwartz (1992) mendefinisikan nilai sebagai sebagai sesuatu yang digunakan oleh individu dalam memilih dan membenarkan tingkah laku serta mengevaluasi tindakan orang lain (termasuk diri sendiri) dan peristiwa yang dihadapinya. Hal yang membedakan antara satu nilai dengan nilai yang lain terletak pada tujuan motivasional yang diekspresikan oleh nilai tersebut. Nilai Sunda pada masyarakat Cianjur tergolong pada nilai tradisi, dimana tujuannya adalah menghargai, berkomitmen, dan menerima kebiasaan dan ide-ide yang berasal dari adat-istiadat, budaya atau agama. Nilai tradisi melambangkan solidaritas kelompok, berbentuk hal-hal yang unik dan berperan dalam kelangsungan hidup (Schwartz, 2006). NilaiNgaos, Mamaos, danMaenpodapatmenunjukkanbahwanilai yang dianutmengandungtradisiuntukmenjunjungtingginilaikeagamaan Islam. Nilaiinidapat diwujudkan dalam beberapa dimensi diantaranya dari sisi Pengetahuan, yaitu seberapa jauh seseorang mengetahui dan memahami ajaran-ajaran agamanya. Lalu Penghayatan, yaitumenyelami perasaan keagamaan yang pernah dialami dan dirasakan seperti merasa dekat dengan Tuhan, dan menghayati bahwa cobaan setiap umat tidak akan melebihi apa yang mampu mereka pikul, termasukadanyabencanaalam. BerikutnyaadalahKeyakinan, bahwaapa yang terjadi adalah seijin Tuhan Yang Mahakuasa. Hal iniakanmengentalkannilaibahwaapa pun yang terjadi, termasukbencanaalamadalahsesuaidengantakdir Allah. BerikutnyaadalahPengamalan, yaitu sejauh mana implikasi ajaran agama mempengaruhi perilaku seseorang dalam kehidupan sosial. 


\section{Journal of Psychological Science and Profesion (JPSP)}

Vol.1, No.1, Desember 2017

E-mail: jpsp@unpad.ac.id

\section{SIMPULAN}

- Terdapat hubungan positif antara Nilai Budaya dan Psychological Well-Being. Hal ini menunjukkan bahwa nilai budaya Sunda yang masyarakat Ciloto-Cianjur anut berhubungan dengan tingkat Kesejahteraan psikologis mereka, dalam menghadapi bencana alam tanah longsor.

- Psychological Well-Being korban longsor berada dalam kategori cenderungRendah. Hal ini menggambarkan kondisi mereka yang merasa kebingungan dan tidak tahu apa yang harus dilakukan dalam mengatasi permasalahan mereka seusai bencana dan meneruskan kehidupan mereka.

- Nilai budaya Sunda masyarakat berada pada kategori Cenderung Tinggi, yang menunjukkan bahwa masyarakat memiliki nilai-nilai. Kesundaan yang menjadi landasan dalam memilih dan membenarkan tingkah laku serta mengevaluasi tindakan orang lain (termasuk diri sendiri) dan peristiwa bencanaalamyang dihadapinya.

- Dengan memanfaatkan nilai budaya, maka intervensi psikososial dapat dilakukan pada masyarakat dengan menyentuh aspek psikologis dan aspek sosial, yang keduanya berkaitan erat dan saling mempengaruhi. Tahapan intervensi yang menyeluruh sangat diperlukan untuk memenuhi kebutuhan fisik, psikis, spiritual, dan sosial sebagai upaya pemulihan kembali kondisi masyarakat yang mengalami korban bencana. Intervensi psikososial yang diberikan paska bencana bertujuan untuk membantu meringankan beban psikologis dan mencegah reaksi psikologis negatif yang muncul paska bencana. Intervensi psikososial dapat mengembalikan individu, keluarga, dan masyarakat agar setelah peristiwa bencana terjadi, dapat secara bersama menjadi kuat, berfungsi optimal dan memiliki ketangguhan menghadapi masalah sehingga menjadi produktif dan berdaya guna kembali.

\section{UCAPAN TERIMAKASIH}

Penelitian ini merupakan penelitian yang didanai melalui skema Penelitian Unggulan Perguruan Tinggi (PUPT). Tim penulis mengucapkan terimakasih yang tak terhingga untuk seluruh pihak yang membantu dan membuat penelitian ini dapat terlaksana. Khususnya pada masyarakat desa CilotoCianjur, Jawa Barat; Kepala Desa Ciloto, Ketua Camat Cipanas, serta tim pendamping yang membantu kelancaran pelaksanaan penelitian di Ciloto-Cianjur, Jawa Barat.

\section{DAFTAR PUSTAKA}

BMKG.Badan Meteorologi Klimatologi dan Geofisika (BMKG) Bandung. www.bmkg.go.id. Diaksespada 16 Mei 2015

BNPB. (2007). Pengenalan Karakteristik Bencana dan Upaya Mitigasinya. Edisi 2. Jakarta.

http://www.cianjurkab.go.id/Content_Nomor_Menu_17_3.html. Diaksespada 16 Mei 2015

LKS SOCINDO. http://www.socindosocialworker.com/LKS SOCINDO, 6 February 2014

Ryff, Carol. (1989). Happiness is everything, or is it? Explorations on the meaning of psychological well-being.Journal of Personality and Social PsychologyVol. 57No.6 pp 1069-1081.

Ryff, Carol dan Corey Lee M. Keyes. (1995). The Structure of Psychological Well-Being Revisited. Journal of Personality and Social Psychology vol 69 no.4.

Ryff, Carol dan Burton Singer. (2002). From Social Structure to Biology : Integrative Science in Pursuit of Human Health and Well-Being. Dalam Snyder, Lopez. 2002. Handbook of Positive Psychology. New York : Oxford University Press, Inc.

Schwartz, Shalom H. (2012). "An Overview of the Schwartz Theory of Basic Values". Online Readings in Psychology and Culture. 2 (1). doi:10.9707/2307-0919.1116

Schwartz, Shalom H. (1992). "Universals in the Content and Structure of Values: Theoretical Advances and Empirical Tests in 20 Countries.". Advances in Experimental Psychology: 1-65

Schwartz, S.H. (1999). Cultural value differences: Some implications for work. Applied Psychology: An International Review, 48, 23-47.

Schwartz, S. H. (2004). Mapping and interpreting cultural differences around the world. In Vinken, H., Soeters, J. and Ester P. (Eds.), Comparing cultures, Dimensions of culture in a comparative perspective. Leiden, The Netherlands: Brill. 


\section{Journal of Psychological Science and Profesion (JPSP)}

Vol.1, No.1, Desember 2017

E-mail: jpsp@unpad.ac.id

Schwartz, S. H. (1994). Beyond individualism/collectivism: New cultural dimensions of values. In Kim, U., Triandis, H. C., Kagitcibasi, C., Choi, S.-C., \& Yoon, G. (Eds.), Individualism and collectivism: Theory, method, and applications.(pp. 85-119). Thousand Oaks, CA: Sage.

Schwartz, S. H. (2006). Value orientations: Measurement, antecedents and consequences across nations. In R. Jowell, C. Roberts, R. Fitzgerald, \& G. Eva (Eds.), Measuring attitudes crossnationally: Lessons from the European Social Survey (pp. 169-203). London: Sage.

Schwartz, S. H. (2007). A theory of cultural value orientations: Explication and applications In Y. Esmer \& T. Pettersson (Eds.), Measuring and mapping cultures: 25 years of comparative value surveys (pp. 33-78). Leiden, The Netherlands: Brill (2007).

Springer, K. W. \& Hauser, R. M. (2006). An assessment of the construct validity of Ryff's Scales of Psychological Well-Being: Method, mode and measurement effects. Social Science Research, 35, 1080-1102. 